\title{
Nuclear Energy Innovation Workshops: Executive Summary
}

Todd Allen, John Jackson, Phil Hildebrandt, Suzy Baker June 2015

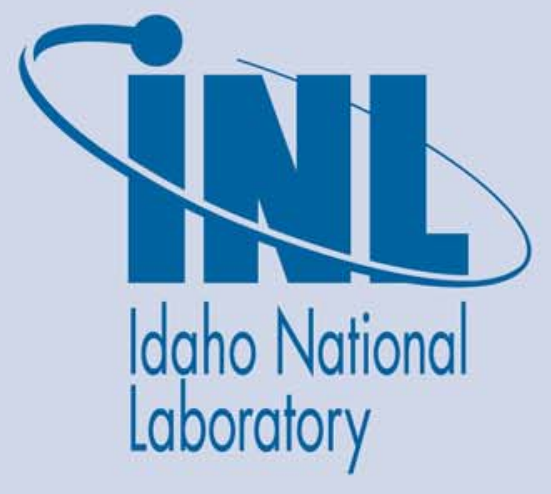

The INL is a U.S. Department of Energy National Laboratory operated by Battelle Energy Alliance 
INL/EXT-15-35042

Revison 2

\title{
Nuclear Energy Innovation Workshops: Executive Summary
}

Todd Allen, John Jackson, Phil Hildebrandt, Suzy Baker

June 2015

\author{
Idaho National Laboratory \\ Idaho Falls, Idaho 83415
}

http://www.inl.gov

Prepared for the

U.S. Department of Energy

Office of Nuclear Energy

Under DOE Idaho Operations Office

Contract DE-AC07-05ID14517 


\section{DISCLAIMER}

This information was prepared as an account of work sponsored by an agency of the U.S. Government. Neither the U.S. Government nor any agency thereof, nor any of their employees, makes any warranty, expressed or implied, or assumes any legal liability or responsibility for the accuracy, completeness, or usefulness, of any information, apparatus, product, or process disclosed, or represents that its use would not infringe privately owned rights. References herein to any specific commercial product, process, or service by trade name, trade mark, manufacturer, or otherwise, does not necessarily constitute or imply its endorsement, recommendation, or favoring by the U.S. Government or any agency thereof. The views and opinions of authors expressed herein do not necessarily state or reflect those of the U.S. Government or any agency thereof. 



\begin{abstract}
Innovation can fulfill an essential role in developing and implementing the strategies and capabilities for improved production and utilization of energy resources. The recently completed Nuclear Energy Innovation Workshops provided intriguing insights into those innovations that are judged - by a diverse sampling of today's nuclear energy enterprise - to be most important and hold the greatest promise. As might be expected, the most frequently discussed innovations are directed toward policy, investment, human capital, and communication of the importance of nuclear energy in achieving an environmentally responsible and economic energy future. Not surprisingly, the most frequently discussed technologically innovative ideas are directed toward enabling further development and commercialization of concepts that are already conceived, but not matured.

The following document outlines the structure of the workshops, summarizes the highlights of the workshop discussions, and suggests the next steps that are warranted.
\end{abstract}




\section{CONTENTS}

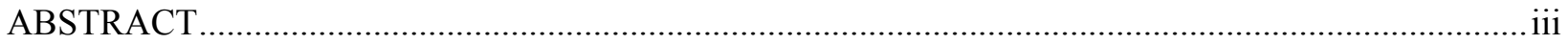

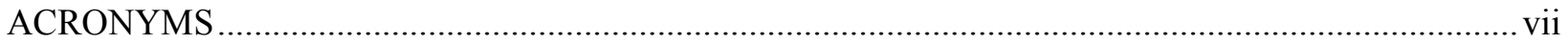

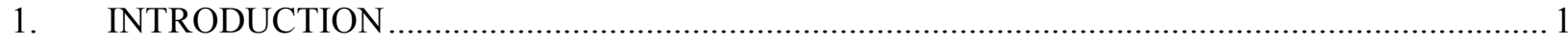

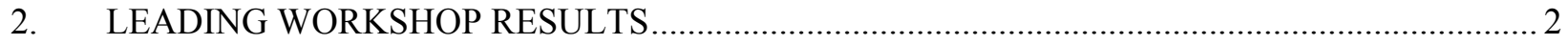

2.1 Develop Better Communications to Reinforce the Value of Widespread Use of

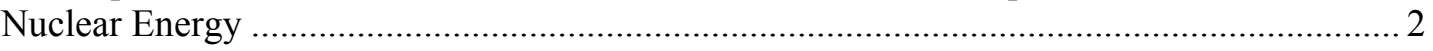

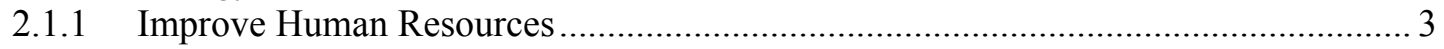

2.2 Designate National Test Beds that Provide Access to Essential Capabilities ........................ 3

2.3 Improve Approaches for Incorporating Advanced Nuclear Energy Technologies in

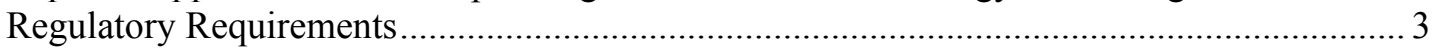

2.3.1 Reinforce Engagement between Federal Agencies, the Research

Community, and Those Parts of Industry That Have An Interest in

Developing Innovative Technologies ................................................................. 3

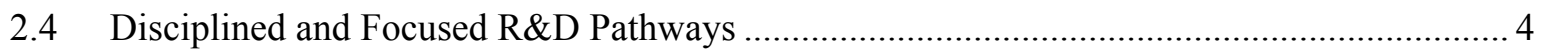

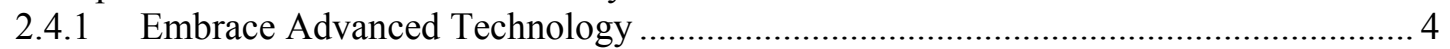

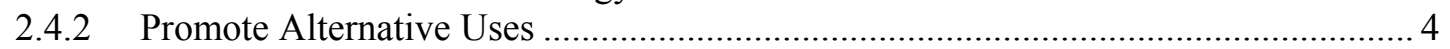

2.4.3 Learn from Other Industries............................................................................. 4

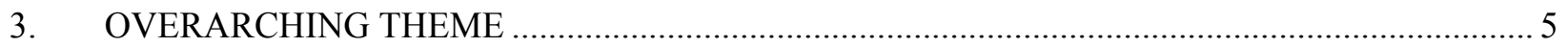

4. INITIAL GLOBAL IMPACT ASSESSMENT OF WORKSHOPS …........................................ 5

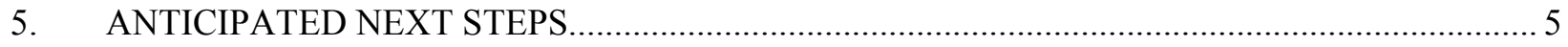

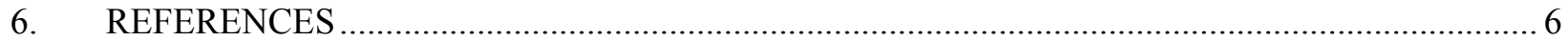




\section{ACRONYMS}

DOE U.S. Department of Energy

NRC Nuclear Regulatory Commission

R\&D research and development 


\section{Nuclear Energy Innovation Workshops Executive Summary}

\section{INTRODUCTION}

An important part of the U.S. Department of Energy (DOE) mission is to encourage innovation in energy production and facilitate its implementation to ensure the efficacy of this production within the U.S. Nuclear energy represents a key component in our nation's technology portfolio to help achieve the goal of providing a clean, secure energy source. Growth of the nuclear industry has been relatively stagnant for several decades and America's historically strong leadership has been steadily eroding. With these thoughts in mind, a set of six simultaneous Nuclear Innovation Workshops were organized by Idaho National Laboratory in order to crowdsource forward-looking ideas for utilizing nuclear energy technologies to help tackle the challenges facing our nation and the world. These workshops were held on March 3-5, 2015 at Oregon State University, Boise State University, University of New Mexico, Ohio State University, Massachusetts Institute of Technology, and North Carolina State University.

The six workshops together represented a diverse cross section of 125 thought leaders selected from universities, national laboratories, federal agencies, industry, and public policy organizations in the U.S. and Europe. Selections were made by the organization team, which included the Idaho National Laboratory leadership team as well as six university hosts and six national laboratory technical leads. The individual workshops were limited to less than 25 participants each in order to provide regional, inclusive atmospheres that were conducive to emergence of local themes.

The workshops were conducted in structured format using collaborative software so that a nationwide ranking of top ideas could be carried out in real time, immediately following the conclusion of brainstorming sessions. Prior to the workshops, participants received a white paper that described the philosophy and established goals for the workshop. During the workshop, four primary focus areas were explored to generate innovative technology ideas supporting the long-term objective of replacing and expanding current nuclear capacity in the U.S., with emphasis on:

- Affordable electricity generation cost with emphasis on capital cost reduction

- Better integration with a dynamic grid with large input from renewable energy

- Enhanced safety and security

- Reduced environmental impact

- Reduced proliferation risk

- Improved resource and waste management.

The four focus areas included innovative concepts; innovative use of existing technologies; an innovative research, development, and demonstration paradigm; and an innovative licensing paradigm. Within these focus areas, several questions were posed for consideration by workshop participants using brainstorming facilitation techniques. Then multiple one-on-one discussions were followed by a bartering-based scoring system to establish the top three ideas for each site. Group discussions then refined topics into consensus ideas, followed by rating and ranking of the likelihood that the innovation idea would positively affect the points of emphasis listed above.

Prior to the workshop participants were urged to focus, to the extent possible, only on technical issues associated with innovation leading to rapid commercialization. Additionally, time constraints prohibited a discussion of innovation in equity investment and debt financing of research, development, demonstration 
and deployment, which is understood to be an important part of the solution. Innovation in advanced manufacturing was captured in a follow-on breakout session at the Advanced Manufacturing \& Supply Chain conference to be held in Pocatello, Idaho on May 18-20, 2015. While policy was generally set aside to allow technical issues to take center stage per original guidance, it naturally became part of conversations.

It is important to place the output from the workshops in appropriate context. Organizers intentionally chose a diverse cross section of participants in order to capture additional perspectives from those who may not be involved in the nuclear industry on a regular basis. The resulting data reflects this diversity and is therefore not always what would be expected from those well versed in nuclear energy systems and energy policy. Further, the predominance of university and national laboratory participants compared with industry representatives created an imbalance with unintentional consequences. Namely, industry input on policy that strongly affects the energy marketplace and industry business decisions was not emphasized in the initial Workshop summaries. It is also evident that the technical community outside of industry generally does not have a deep understanding of how regulatory requirements are established and the processes for licensing and regulation of nuclear energy technologies by the Nuclear Regulatory Commission (NRC). These topics are considered possible opportunities for future focused innovation workshops.

\section{LEADING WORKSHOP RESULTS}

An exercise conducted at the conclusion of the workshops involved site by site summarization that was shared live with all sites. A national laboratory technical lead from each site collected local leading topics of conversation as well as consistent themes that emerged during brainstorming sessions. Although regional focus was encouraged through careful selection of participants as well as guidance from organizers, regional themes did not generally emerge with a few exceptions.

The themes summarized below represent those that emerged during this final exercise and during selected discussions within the individual workshops. Responses to the questions posed by organizers during the workshops are extensive and not included in this executive summary. These will be discussed in the final report. Some of the top thematic areas under which innovative suggestions were made are:

\subsection{Develop Better Communications to Reinforce the Value of Widespread Use of Nuclear Energy}

There is growing, international recognition of nuclear energy's value in providing economically stable and environmentally clean energy. Communicating this value in a simple, evidence-based way is necessary. Successful outreach must credibly emphasize the importance of nuclear energy for a prosperous and environmentally responsible future. Prevalent in workshop discussions was the suggestion that efforts should be made to educate the public via outreach programs (e.g., frequent television spots analogous to those from the American Petroleum Institute, America's Natural Gas, and the American Coalition for Clean Coal; stronger emphasis on nuclear energy as a clean energy source in K-12 education programs; educational seminars for local and regional consumption). Another potential outreach example cited at the Ohio State University workshop was an idea to develop seminar series or workshops in the academic and national laboratory environment that address questions such as:

- How was nuclear energy technology derived from and intentionally separated from nuclear weapons development?

- Why is the light water reactor technology the current dominant choice in the U.S. and world-wide for nuclear power? 
- What are the important drivers that will influence industry use of advanced nuclear energy technologies?

\subsubsection{Improve Human Resources}

Less directly related, but related nonetheless to improvement in communication are improvements in human resources within the nuclear industry. Workshop comments touched on topics such as addressing knowledge transfer vulnerabilities and focused education programs. Generally, methods for improvement in education and leadership within the nuclear energy community were put forth.

\subsection{Designate National Test Beds or Platforms that Provide Access to Essential Capabilities}

An expansion of current R\&D capabilities to provide more extensive support for fundamental technology development in support of nuclear energy is needed. Additionally, characterization of, and appropriate improvement of the infrastructure at national laboratories is needed to help support commercialization. One of the most commonly cited reasons for lack of innovation in nuclear energy is the difficulty associated with access to facilities and infrastructure necessary for carrying out highly specialized and often quite hazardous studies that are fundamental to ensuring safety and reliability in nuclear reactors. The test bed concept could range from fundamental research platforms where separate effects testing are performed to reduce technical risks for a developmental nuclear energy technology to a full scale reactor prototype that demonstrates operational performance of maturing technology to support commercialization. The concept and scope of such test beds require considerably more discussion and is a candidate for a near-term focused workshop. Development of such infrastructure, along with facilitated access and regulatory oversight commensurate with development and demonstration activities, are suggested as requirements for the advancement of nuclear energy in the U.S. and the world. Regulatory guidelines (NUREG-1537, Guidelines for Preparing and Reviewing Applications for Licensing of NonPower Reactors) already exist that complement commercial power reactor licensing and apparently could enable an appropriately regulated national test bed or test platform.

\subsection{Improve Approaches for Incorporating Advanced Nuclear Energy Technologies in Regulatory Requirements}

As established by Congress, today's regulatory priorities focus on the existing nuclear energy fleet. Some innovative and advanced nuclear concepts are in process with NRC, but there is a common perception that the U.S. regulatory process inhibits innovation. Congressional realignment of NRC's priorities and a cooperative approach by NRC and DOE are warranted to encourage innovative and advanced nuclear energy concepts. This approach can utilize the Office of Nuclear Reactor Regulation research and test reactor licensing processes for research and development activities for innovative and advanced nuclear energy technologies and the Office of New Reactors processes for commercialization and construction of facilities utilizing such concepts. Early cooperative activities are warranted from DOE and NRC to establish the fundamental regulatory requirements for such technologies and the utilization of reactor test bed concepts.

\subsubsection{Reinforce Engagement between Federal Agencies, the Research Community, and Those Parts of Industry That Have An Interest in Developing Innovative Technologies}

DOE, NRC, and parts of the industry that have an interest in development of innovation or can identify issues important to maintaining the current fleet should be working closely together. Sharing ownership of research, development, and demonstration improves synergy in several areas including: 
regulation and enhanced understanding of the approach to setting safety criteria and design requirements, fundamental research and development (R\&D) necessary to address modern issues (i.e., industry informs federal R\&D programs), and innovative insight provided by federally-supported scientists.

\subsection{Disciplined and Focused R\&D Pathways}

Improved stability of nuclear R\&D funding is vital and should include a specific set of clear, long term, national priorities that extend multiple decades. There is need for a consistent and long standing policy on energy; the Quadrennial Energy Review and Quadrennial Technology Review were commissioned for this reason. It is likely that these need time to mature. Although this is generally a policy issue involving Congress, Office of Management and Budget and the DOE, it surfaced multiple times during the workshops. Some themes branch from this with regard to potential focused R\&D pathways.

\subsubsection{Embrace Advanced Technology}

Multiple examples of existing or near-term technologies (digital instrumentation and control, modular construction, passive safety systems, high-temperature reactors) could be implemented by the nuclear enterprise if the economic and safety cases are compelling. The discussion also included opportunities for innovation in the nuclear fuel cycle. Several ideas posed during the workshops were subsequently ranked according to level of innovation, industry impact and feasibility of implementation. These ideas were proposed in response to the question: "In the area of nuclear energy systems and subsystems, where are the greatest opportunities for innovation?" The idea ranked most innovative by combined voting of all workshop participants was direct nuclear to electric energy conversion. Direct conversion was perceived to be a highly innovative solution for advanced nuclear power stations to address issues including safety, regulatory issues and possible increases in efficiency. Ideas that were judged by participants to be the best combination of impact and feasibility while maintaining an appropriate level of innovativeness were (1) development and demonstration of advanced reactor design(s) that are truly inherently safe; (2) development of Brayton and other high-efficiency energy conversion systems with minimal water consumption, which is important in arid regions; and (3) technologies that accommodate variable production where traditional base-load operation must be modified to address dynamic load and production conditions on the grid.

\subsubsection{Promote Alternative Uses}

Process heat has high potential for use in chemical processes, fossil fuel extraction, etc. Often discussed previously, this was a frequent topic of discussion among participants primarily in response to a question related to positive synergy between nuclear energy and other industries.

\subsubsection{Learn from Other Industries}

Site summaries suggested studying examples of success in other industries, including socialization, regulatory models (Federal Aviation Administration, pharmaceutical, etc.), and construction techniques. The nuclear community could benefit from proactively adopting lessons learned from other industries. Foremost among lessons suggested for adoption were those related to regulatory oversight. This theme appears in response to questions regarding synergy between nuclear energy and other industries as well as to a question involving improvement of the regulatory paradigm.

An "X-prize" type approach was suggested multiple times during the workshop. This approach has seen varying degrees of success in promoting rapid development of cost effective and advanced space flight. The motivation for this type of approach, the so-called "Ansari X-prize," originally was a cash award provided by a group of entrepreneurs to the winner of a competition to be the first non-government 
organization to launch a reusable, manned spacecraft into space twice within two weeks. Potential for innovation in advanced nuclear energy systems is perceived to be enhanced by a more openly competitive "blue sky" approach.

\section{OVERARCHING THEME}

Overarching to these themes were private conversations suggesting that the U.S. Government should further encourage private sector investment in the development and commercialization of innovative nuclear energy technologies and advanced nuclear energy systems. A number of private interests of varying size are already investing in the early development of advanced nuclear energy systems. This can be further encouraged through broader use of grants and cooperative agreements per 10 CFR 600 that can encourage development and eventual commercialization of promising innovative and advanced concepts. Grants can be focused on early startups and cooperative agreements on cost-shared public-private partnerships to assist in defraying the considerable costs associated with commercialization of nuclear energy technologies.

\section{INITIAL GLOBAL IMPACT ASSESSMENT OF WORKSHOPS}

Both traditional and social media outlets were utilized to communicate about the workshops while in progress. These activities generated approximately 4 million interactions on Twitter and an Associated Press article about the events ran in at least 150 news outlets in 31 states and six countries. Publication of the article included the New York Times, the Washington Post, and ABC News. A number of in-depth and ongoing conversations were established both on and offline as a result of these social interactions. The level of public dialogue surrounding the workshops is a positive indicator that the recommendations of the event are timely and socially supported.

\section{ANTICIPATED NEXT STEPS}

A more comprehensive summary report containing discussion that reflects additional detail anticipated from the large volume of ideas and comments recorded by participants will be completed over the next several months. The report will contain recommendations for a path forward and for DOE Office of Nuclear Energy focus.

Initial thoughts on potential next steps include the following:

- Focused workshops on several of the emergent innovation themes resulting from this workshop. Examples include development of a national test bed, human resources in nuclear, government encouragement of private investment, improved regulatory development for innovative and advanced technologies, etc.

- Diversification of input. It is recognized that learning from other industries is applicable to innovation in nuclear power. It is also recognized that input from those not generally involved in the nuclear industry, or those who are thought leaders in initiatives such as clean energy, may offer valuable insight.

- Implementation of innovative ideas into DOE R\&D roadmaps. 


\section{REFERENCES}

10 CFR 600, "Financial Assistance Rules," Code of Federal Regulations, Office of the Federal Register, May 2015.

NUREG-1537, 1996, Guidelines for Preparing and Reviewing Applications for Licensing of Non-Power Reactors, U.S. Nuclear Regulatory Commission, February 1996. 